\title{
The New Role of Industrial Engineers May Not Include Traditional Industrial Engineering Practices
}

\author{
Michael Sanders, Ph.D. \\ Phone: (810)762-7947 \\ Email: sanders@kettering.edu \\ Kenneth Morrison, Ph.D. \\ Phone: (810) 762-7941 \\ Email: kmorriso@kettering.edu \\ Industrial \& Manufacturing Engineering \& Business \\ Kettering University \\ 1700 West Third Avenue \\ Flint, MI 48504, USA \\ Fax: (810) 762-9924
}

\begin{abstract}
Keywords:
Industrial Engineering, Global Manufacturing System, Supply Chain System, ERP, MicroIE, Macro-IE, Lean System, NON-Value-added Activity, Process Modeling, Process Improvement, Web Applications.
\end{abstract}

\begin{abstract}
The current engineering education focuses on fundamental engineering concepts that have been taught for many decades. Many programs in industrial engineering offered in various universities are often structured in a way that exhausts topics such as process diagnosis, control, and improvement. These programs consider quality, work design and ergonomics, and material flow as the central theme of their curricula. However, they do not focus on the systems view of organizations as much as they should, specifically during the time of organizational change.

Due to the recent technological advancement in information technology and opportunities provided by the Internet, many playing fields in the manufacturing industry have changed to reflect rapid market changes and requirements. This includes globalization of manufacturing functions and activities, hence creating a set of new challenges to Industrial Engineers (IEs) in the organizations. Recently, we have learned that General Motors (GM) Corporation has been seriously considering a dramatic change in their industrial engineering departments worldwide. There has even been talks in GM regarding elimination of industrial engineers and distributing their main functions and activities to the process operators. Many other manufacturing organizations are mainly focusing on the process and system changes and improvement as they link to the ir overall industry supply chain. Therefore, these organizations seek industrial engineers with more knowledge and education in systems engineering and optimization than process improvement and operator safety. In addition, the
\end{abstract}


introduction and implementation of improvement initiatives such as Lean Manufacturing system has resulted in reduction of traditional activities of IEs.

This paper focuses on a new role of industrial engineers as they are being redefined by the manufacturing industry in the field. It explains the results of a pilot study on IE's new required roles in a large corporation. This paper also discusses a new wave of business/enterprise solutions that are aimed to optimize organizational effectiveness and efficiency by IEs.

\section{MIGRATION FROM MICRO-IE TO MACRO-IE}

The recent technological advancement in Information and Communication Technology (ICT) has created profound impacts in the use of resources particularly time and money by the production systems when they aim to improve their efficiency and effectiveness. That is, the faster and less costly the improvement efforts are, the quicker organizations accept to implement them. However, the changing times in production systems has proven to have one major obstacle: the cultural change. Because of this hurdle, the leaders of organizations have learned to be extra careful on the promises made by their selected improvement philosophy. They have decided to invest more on sustainability of improvement and longevity of benefits to their stakeholders, primarily their customers and employees. As a result, improvement initiatives that offer comprehensive and fundamental cultural and structural changes are more and more preferred by business leaders. Two of most widely accepted and commonly implemented improvement philosophies during the recent years are Lean Production Systems (LPS) and Six Sigma among the US industries. Although the name has been changed to reflect the organization's individuality, the principles of LPS, pioneered by Toyota Corporation as Toyota Production System (TPS), have been heavily adopted and practiced by big three US auto makers (General Motors Corporation, Ford Motor Company, and DaimlerChrysler Corporation). The Six Sigma approach, pioneered by Motorola Corporation, has been revitalized and widely practiced by General Electric Corporation (GE). In both cases, numerous success stories are recorded in the literature.

Organizations that have implemented or are implementing LPS or Six Sigma are naturally redesigning their organizational structure and redefining their employees' functionalities (i.e., changing their organizational culture). This process of change has and is seriously affecting the role of industrial engineering in these organizations. For example, General Motors Corporation has been implementing LPS under their own name called General Motors Global Manufacturing Systems (GM-GMS) for the past several years. GM defines Global Manufacturing System as "a single, common, competitive manufacturing system, consistent with Quality Network Principles, using best processes, practices, and technologies to support General Motors' Vision of World Leadership and Global Customer Ent husiasm" (General Motors, 2002). More specifically, our investigation on GM-GMS indicates that GM has developed it to implement lean manufacturing principles in current and future production processes, in correlation with its Business Priorities. These principles include the following: Continuous Improvement, Standardization, Built-In Quality, Short Lead Time, and People 
Involvement (GM-GMS Guide, 1999). These five principles of GMS, illustrated by Figure 1, are initiated in process redesign and redefinition.

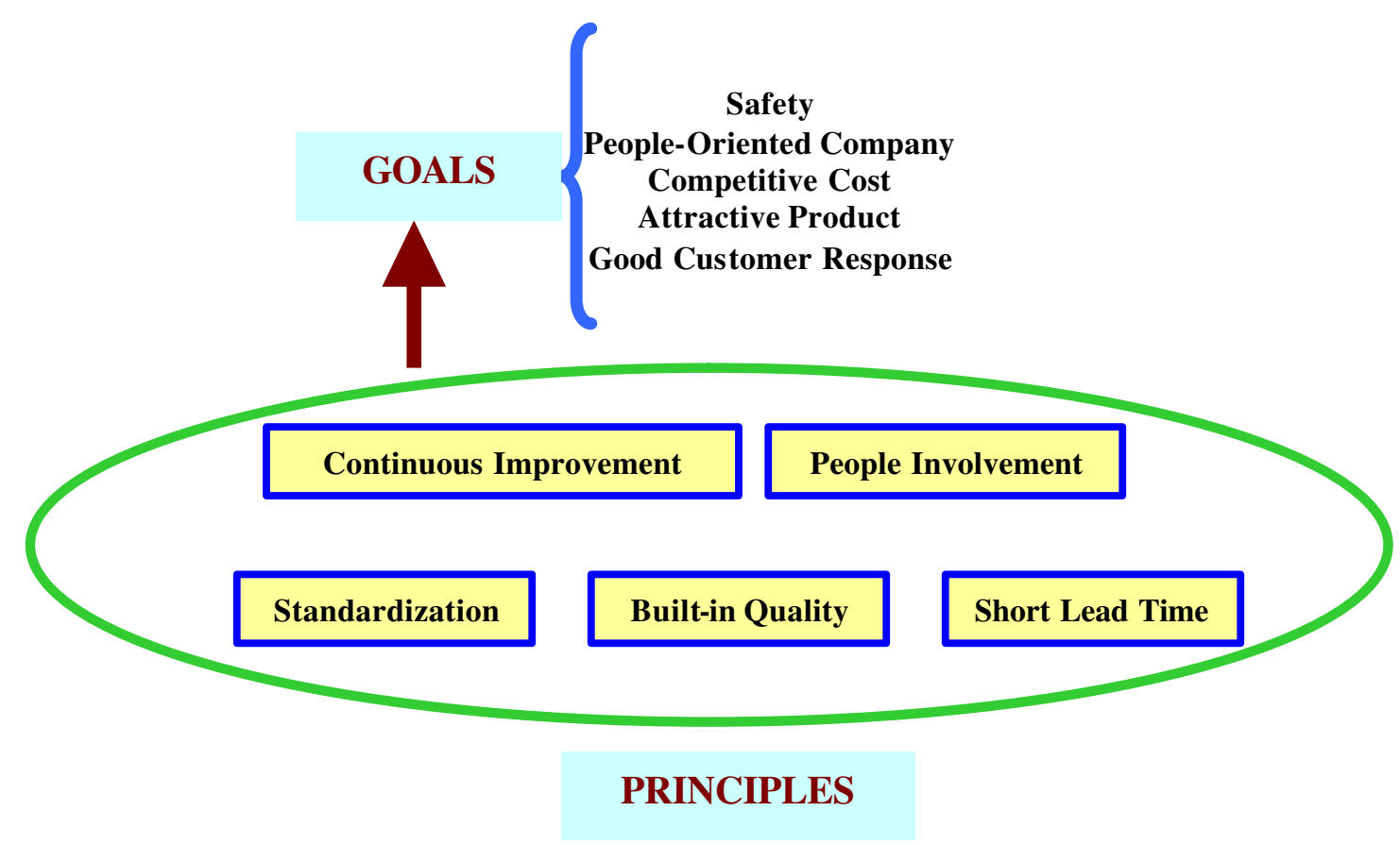

FIGURE 1: GMS Goals and Principles

Our investigation further revealed that industrial engineering has established and supervised production systems in every one of the General Motors facilities for many decades, but with the implementation of GMS, the role has been changed resulting in significant cost manage ment implications (Rodriguez, 2003). For example today at GM, industrial engineers are heavily involved in identifying the operational financial issues and, in many instances, helping with accounting/finance functions. These are activities that they did not traditionally practice as a regular part of their responsibilities. According to GM's management, these changes are the result of implementing GMS that inherently includes many of traditional IE functions and activities. These activities either are embedded within the GMS process redefinition, eliminated/standardized or are shifted to floor/line operators. Among these activities include time and motion study, statistical process control activities, work place design, and many human factors/ergonomics related principles for operator safety.

By the use of advanced computer software modeling and simulations devices, the production processes are redesigned and the related activities are redefined accordingly. With the role changes, the title change has taken place and industrial engineers at GM are now re-titled to Competitive Operation Engineer (COE) (Rodriguez, 2003). As a result, under GM's Global 
Manufacturing System structure, the traditional role of the Team Leaders (TL) in GM is also significantly changed, assuming more responsibilities from traditional IE functions. Among these new IE flavored duties for Team Leaders are (Holiday, 2004):

- Safety - recognition and assurance of a safe work environment for everyone entering the team

- Quality - identification, control, and elimination of causes of defects, not allowing them pass to the next process

- Production - responding to work environment to meet production schedule

The increasing use of virtual factory environments allows these GMS principles to be properly planned. As opposed to the traditional approach in which IEs were primarily called upon for investigating and designing a process or the whole assembly/manufacturing floor plan, now they are required to become a true systems integrators and by the use of the latest simulation technologies, to present a completed process flow in a virtual environment.

Because GMS primarily integrates the commonly-practiced engineering and management tools and techniques in its structure and implements them in the production system as embedded sub-processes or production steps, the traditional use of these tools by IEs have been reduced dramatically. Other usages related to these tools, e.g., statistical process control, that were the backbone of quality engineers' activities (from IE departments), have now been integrated to software applications that rely on databases which are readily measured and collected at the production lines. Many Enterprise Resource Planning (ERP) applications include comprehensive modules that conduct statistical process control activities and create real time reports to the line operators who are trained to recognize out of range problems and solve them on the spot. In other words, majority of these conventional IE functionalities have been captured by standardization and built-in quality elements in production systems which use Lean principles and in the case of GM, GMS principles.

\section{EXTENDING IE FUNCTIONS TO BEYOND THE ORGANIZATION}

Our investigation has further revealed that for the most part industries, especially manufacturing, require their new engineers to have necessary knowledge of latest developed software applications in systems optimization and process modeling. Those applications which are interrelated and integrated with various functions of an organization, offer relational functionality among material movement, mater operation scheduling, and key performance indicators. These requirements are also extended to understanding of industry supply chain, as opposed to merely focusing on internal issues of an enterprise i.e., production system.

The process view of a supply chain offers a simplified approach to measuring its effectiveness and efficiency (i.e., performance). It allows us to optimize the supply chain process by improving any of its member entity's production system, as it links to the other entities in the chain. All entities in a supply chain process are focused to meet the end users' expectations, not just satisfying the next entity in the chain. This focus on the ultimate customer is possible when lean production system (LPS) principles are coupled with the latest on-line delivered extended enterprise software applications. The LPS provides a standardized method of eliminating waste and promoting valueadded activities, thus enhancing the efficiency and effectiveness of the production system. 
There is a new trend in organizational optimization and management system that suggests use of such principles as lean coupled with web based applications that allow faster and less costly material movement, manufacturing/assembly operations, and performance measurement through the Internet. Literature indicates that these developments have been possible by using industrial and systems engineering principles. Even software application organizations, whether in design, development, manufacturing, material handling, inventory control, or distribution, have relied on IEs in the recent years to make their products more marketable in line with the requirements of improvement philosophies, that is to follow systems approach (Langenwalter, 2000). These organizations are hiring more IEs that before (Baan, 2002) mainly because they view IEs to have the best fit background in systems solutions. Therefore the need for industrial engineers who are more trained and educated in macro-IE is becoming more accepted in the market than before.

\section{CLOSING REMARKS}

Our investigation at General Motors on Global Manufacturing System and its effect on the role of industrial engineers has been a pilot study that definitely requires further research. Realizing that this paper could not share many of specific findings due to confidentiality issues with GM, in our view it has been able to present a clear view on the rapidly changing activities and roles of industrial engineers in production systems.

In our view, understanding systemic changes in production systems based on improvement initiatives and managerial/engineering philosophies is more important than ever before for industrial engineers both in the field and in academic institutions as well. Industrial engineers are required to be equipped with knowledge of the systems view of organizations as integrated processes through process based discipline (Sanders, et al, 1999). Through initia tives like Lean Production System we have realized that identifying and eliminating wastes in all categories are more effectively achieved if the solutions are embedded in the processes. Using industrial engineering tools and techniques in improving the production process and operator performance every time there is a need by a select group of specialized employees (i.e., IEs) are viewed as non-value added activities by organizational leaders who have adopted systemic changes in their production systems. Therefore, these leaders are looking for newly hired engineers who are tooled with understanding the holistic view of organizational change and offering new process designs and redefining new process functions in the context of a whole organization.

Finally, according to our findings, we recommend that higher education institutions to reevaluate their programs in industrial engineering and include systems approach with the latest organizational optimization software applications in mind. We hope to continue our investigation and present a much deeper research results in the changing role of IEs. 


\section{REFERENCES}

1. Baan, Jan (2002) The Keynote Address, The Proceedings of University Synergy Program (USP) 2002 International Conference, Putten, the Netherlands.

2. General Motors Corporation, Global Manufacturing System guide, November 1999.

3. General Motors Corporation, "General Motors Global Manufacturing System (GMGMS) Principles, Elements, \& Core Requirements," November, 2002.

4. Holiday, John (2004) The Changing Role of the Team Leader Amidstthe Greenfield Site, Student Fifth Year Thesis, Kettering University.

5. Kolarik, William J. (1999) Creating Quality: Process Design for Results, WCB/McGrawHill, New York, NY.

6. Langenwalter, Gary (2000) Enterprise Resource Planning and Beyond: Integrating Your Entire Organization, the St. Lucie Press/APICS Series on Resource Management, New York, NY.

7. Rodriguez, Eric T (2003) The New Role Of Industrial Engineering In The Global Manufacturing System, Student Fifth Year Thesis, Kettering University.

8. Sanders, Michael S. and Matthew Sanders (2000) Measuring Process Knowledge As a Performance Indicator in Implementation of Enterprise Systems, $3^{\text {rd }}$ Annual University Synergy Program, Haifa, Israel, September 2000.

9. Sanders, M., S. Patro, and W. J. Kolarik (1999) Effective Application of ERP Systems in $S M E s$, Second Annual International University Synergy Program Conference, Utrecht, The Netherlands.

10. Taylor, Frederick Winslow, the present state of the art of industrial management, Harper. New York, 1991 